\title{
PULMONARY ATELECTASIS AFTER ANAESTHESIA: PATHOPHYSIOLOGY AND MANAGEMENT
}

\author{
JOHN R.A. RIGG
}

\begin{abstract}
The pathophysiological basis of pulmonary atelectasis is reviewed and risk factors that enhance lung collapse are discussed. Management strategies to reduce or eliminate risk factors and to prevent collapse are discussed and the rational bases of these strategies are identified.

Instability of lung alveoli is a consequence of surface tension and regional differences in alveolar size. The inherent tendency of alveoli to collapse is enhanced by the following risk factors; low lung volume, high closing volume, oxygen therapy, a rapid shallow ventilatory pattern, chronic lung disease, smoking, obesity, postoperative pain following abdominal or thoracic surgery, narcotic induced ventilatory depression, and neurological, neuromuscular, muscular and musculoskeletal diseases as sociated with mechanical impairment of respiratory function. The primary goal of perioperative respiratory management is prevention of atelectasis. Appropriate management strategies include physiotherapy and delay of elective surgery if substantial improvement in respiratory status can be achieved by specific treatments such as antibiotics, bronchodilators, steroids, and reduction of tobacco use and caloric intake. In selected cases, elective postoperative controlled ventilation may be indicated.
\end{abstract}

Key Words: Anaesthesia, Complications, atelectasis; Lung, atelectasis.

LUNG COLLAPSE and infection leading to acute respiratory failure is a major cause of post surgical morbidity and mortality. ${ }^{1.2}$ Small areas of "silent" pulmonary atelectasis develop insidiously and frequently precede overt clinical evidence of lung collapse and other associated postanaesthetic pulmonary problems. ${ }^{3}$ It is the purpose of this paper to review the pathophysiology and pathogenesis of pulmonary atelectasis and the physiological basis for pulmonary management in the postoperative period.

\section{Pathophysiology and Pathogenesis of ATELECTASIS}

The inflated lung is inherently unstable; in other words, it tends to collapse spontaneously, an observation that may be confirmed directly in the apnoeic lung at thoracotomy. The tendency to collapse results from two fundamental physical characteristics of the intact lung and is

John R.A. Rigg, M.B., B.S., F.F.A.R.A.C.S., Associate Professor, Department of Anacsthesia, McMaster University.

Address for Correspondence: Dr. John R.A. Rigg, W.K. Kellogg Centre For Advanced Studies In Health Sciences, Western Australian Institute of Technology, Hayman Road, South Bentley, Western Australia, 6102.

Canad. Anaesth. Soc. J., vol. 28, no. 4, July 1981 further enhanced by many other factors, some of

The first physical characteristic is the presence of surface tension at the gas liquid interface of the alveoli. In an isolated alveolus, assumed to be spherical in shape, ${ }^{*}$ the pressure $(P)$ tending to collapse that alveolus is given by the following expression of Laplace's Law-

$$
\mathrm{P}=\frac{2 \mathrm{~T}}{\mathrm{r}},
$$

where $\mathrm{T}=$ surface tension and $\mathrm{r}=$ radius of curvature of the alveolus. ${ }^{4}$

This relationship indicates that the pressure tending to collapse the alveolus is directly proportional to the surface tension at the alveolar lining and inversely proportional to the radius (or the size) of the alveolus.

*It is recognised that the spherical balloon model is a considerable simplification of alveolar shape. A more precise equation to compute the collapsing pressure within non-spherical objects is given by $P=T_{1} / r_{1}+$ $T_{2} / r_{2}$, where $r_{1}$ and $r_{2}$ are the principal radii of curvature and $T_{1}$ and $T_{2}$ corresponding surface tensions. ${ }^{4}$ However, the arguments presented here concerning the pathogenesis of atelectasis are no less valid for the assumption of spherical alveoli and the use of the classical Laplace equation. 
The second physical characteristic is nonhomogeneity of the lung. Non-homogeneity refers to regional differences in lung structure and function and is due to the action of gravity; that is, the weight of the lung itself. The effect of gravity causes a gradient of pleural and transpulmonary pressure from non-dependent to dependent lung regions, which in turn causes regional differences in the mechanical properties of the lung, the pattern of ventilation and gas exchange (Figure 1). ${ }^{5-8}$

Figure 1 shows a gradient of alveolar sizes from alveoli of relatively large radii of curvature in non-dependent regions to alveoli of relatively small radii of curvature in dependent regions. Consideration of the Laplace equation indicates that smaller alveoli are more unstable than larger alveoli, tend to collapse more readily, and to empty into large alveoli. This explains the observation that overt pulmonary collapse more frequently occurs in dependent lung regions. ${ }^{9}$ This tendency may be demonstrated by the simple experiment of connecting two partly inflated balloons and observing that the smaller balloon will always empty into the larger balloon.

The tendency of alveoli to collapse is reduced substantially by the presence of surfactant, a lipid material containing the important constituent dipalmitoyl lecithin which is secreted by Type II alveolar lining cells. Surfactant has two important effects which promote alveolar stability. First it lowers surface tension in all alveoli, thereby decreasing the pressure tending to collapse them. Secondly, it decreases surface tension as alveolar radii of curvature diminish during expiration, thereby minimizing the pressure changes that increase the tendency to collapse. Conversely, the absence of surfactant or impairment of its production promotes alveolar instability and overt lung collapse.

The above considerations indicate that low lung volume tends to promote atelectasis and provides a rational basis for therapeutic manoeuvres designed to increase lung volume. ${ }^{2}$ Additional mechanisms contributing to the development of atelectasis are airway closure, which promotes absorption of trapped gas; ${ }^{4}$ oxygen therapy, which enhances absorption atelectasis; the pattern of ventilation and regional mismatching of ventilation $(\dot{V})$ and perfusion $(\dot{Q})$. Pulmonary disease enhances both airway closure and regional $\dot{V}$ and $\dot{Q}$ mismatching.

Airway closure is the term applied to the functional closure of small airways, occurring predominantly in dependent lung regions during

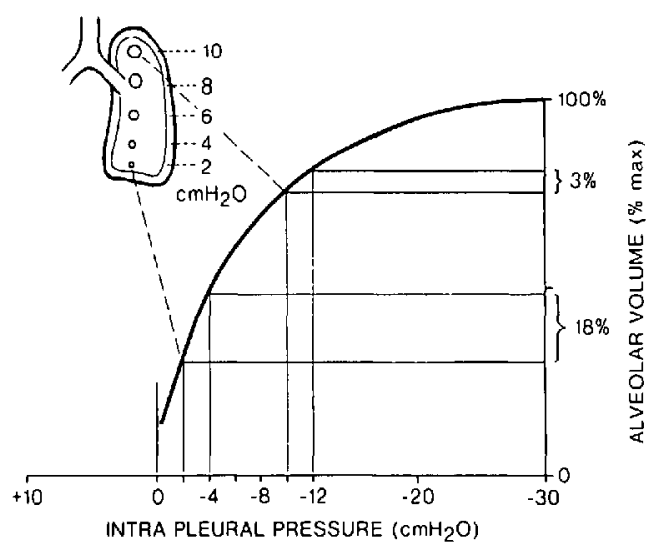

FIGURE 1 Schematic representation of regional differences in the lung due to the action of gravity. Intra-pleural pressure is least in non-dependent lung regions and greatest in dependent regions. At resting lung volume, non-dependent alveoli are more distended and less compliant than dependent alveoli. As a consequence, dependent alveoli tend to increase volume on inspiration more than non-dependent alveoli for a given absolute intrapleural pressure change. The smaller radius of dependent alveoli makes the alveoli more susceptible to atelectasis (see text for detailed explana. tion).

expiration. ${ }^{4}$ The site of airway closure is probably the region of the respiratory bronchioles. In individuals with normal lungs, airway closure occurs only at very low lung volumes. However, in patients with airways disease and in elderly patients with apparently normal lungs, airway closure may occur near or above FRC. Airway closure implies distal gas trapping and underventilation and, since it occurs mainly in dependent lung regions, it leads to substantial regions with low ventilation-perfusion ratio $(\dot{V} / \dot{Q})$. Airway closure thus promotes the tendency to collapse in these regions, a tendency enhanced by oxygen therapy. ${ }^{10}$

The role of absorption atelectasis - and how this phenomenon is enhanced by oxygen - is shown in Figure 2. If an airway is occluded by a mucous plug, or if airway closure occurs, gas is trapped in distal alveoli. These alveoli will be exposed to blood in the pulmonary capillary from the right side of the heart, in which the sum of the partial pressures of all gases is less than the sum of the partial pressures of these gases in the alveolar gas phase. This pressure differential favours continuing uptake of trapped gas into the pulmonary circulation and leads to progressive alveolar atelectasis. This pressure differential is much greater if oxygen-enriched mixtures are breathed and this favours more rapid progression of absorption atelectasis ${ }^{10-13}$ (Figure 2). 


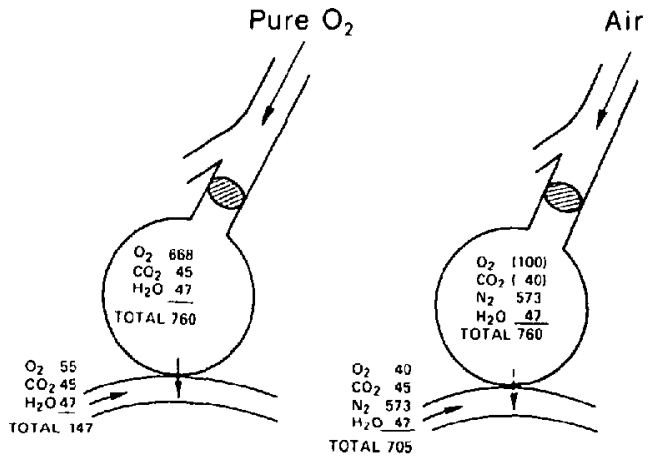

Figure 2 The development of atelectasis in lung regions distal to blocked airways $(A)$, when oxygen and (B) when air is breathed. In both cases, the sum of the gas partial pressures in mixed venous blood is less than in the alveoli. In (B) the $\mathrm{PO}_{2}$ and $\mathrm{PCO}_{2}$ are shown in parentheses because these values change with time. However, the total alveolar pressure remains within few a mmHg of 760 .

Another factor influencing the rate of development of atelectasis is barometric pressure. In a blocked lung segment the number of oxygen molecules per unit lung volume is directly proportional to the barometric pressure. Thus each molecule occupies a proportionally larger lung volume at low ambient pressure. It follows that the rate of absorption atelectasis will be inversely related to barometric pressure, a fact that has been well documented in man ${ }^{11,15-18}$ and in experimental animals. ${ }^{19,20}$

It is clear that low $\dot{V} / \dot{Q}$ areas in dependent lung regions, i.e., areas of relative underventilation, are predisposed to the development of progressive atelectasis. Any influence that enhances underventilation will increase this tendency. The most important of these risk factors is airways disease, particularly chronic bronchitis and/or emphysema. ${ }^{21-23}$ In chronic airways disease, inspired gas distribution is more uneven, both temporally and spatially. In addition, airways obstruction increases the time constant for optimum alveolar gas filling, further impairing intraalveolar inspiratory gas distribution. Another common influence augmenting the tendency to collapse is a rapid shallow pattern of ventilation, commonly seen in patients with obesity and in postoperative pain, when the discomfort of an abdominal or thoracic incision inhibits inspiration. ${ }^{24.25}$ The latter problems may be compounded by the use of sedative and narcotic analgesics, which depress ventilation further, in addition to suppressing the cough reflex and retarding sputum clearance. ${ }^{26-31}$ The incidence of atelectasis after narcotic administration has been shown to be dose related. ${ }^{32}$

Depressed central respiratory drive due to chronic obstructive lung disease, neurological disease or hypoventilation syndromes may also aggravate the tendency to atelectasis. ${ }^{33-37}$ Reduced inspiratory reserve due to peripheral neural (Guillain-Barre syndrome, spinal cord injury), neuromuscular (myasthenia gravis, postanaesthetic persistent curarisation syndrome), muscular (the muscular dystrophies) and musculoskeletal disorders (ankylosing spondylitis, thoracoplasty, kyphoscolosis) may also be associated with a shallow pattern of breathing, increased hypoventilation of dependent lung regions and an enhanced tendency to atelectasis (Table I). ${ }^{37}$

The type of surgery markedly influences the possibility of postoperative atelectasis. ${ }^{2}$ If the pleura or peritoneum are not opened, the incidence of atelectasis is less than one per cent. ${ }^{38.39}$ This applies to head and neck, breast, anal and transurethral surgery. In contrast, lower abdominal surgery is associated with 10 per cent, and upper abdominal surgery a 20 per cent incidence of atelectasis. ${ }^{2,38.39}$

Elderly and obese patients and those with upper respiratory tract complications are more likely to develop atelectasis. ${ }^{40-42}$ Smoking increases the incidence of postoperative atelectasis in a dose-related manner. ${ }^{43}$

\section{Management}

The primary goal of perioperative respiratory management is prevention of atelectasis. Prevention of atelectasis must begin in the preoperative period with the physician, surgeon or anaesthetist recognising the risk factors and instituting the appropriate action preoperatively to minimize the potential for postoperative lung complications that begin as atelectasis. Table I enumerates these risk factors and summarizes appropriate actions.

Frequently a patient is discovered to have major risk factors within 24 hours of proposed elective surgery. If substantial reduction of risk can be achieved by a five to seven day period of intensive respiratory therapy, then definitive elective surgery must be postponed. In many cases of semi-elective and even semi-urgent surgery, the surgical outcome may be improved if the operation is delayed to allow preoperative pulmonary therapy. ${ }^{37}$

Patients with acute upper respiratory infection 
TABLE I

Perioperative Risk Factors and Management Strategies to Minimize the Possibility of Pulmonary atelectasis

\begin{tabular}{|c|c|}
\hline Risk Factors & Management Strategies \\
\hline \multicolumn{2}{|l|}{ Preoperative and Postoperative } \\
\hline 1. Acute Respiratory Infection & Delay elective surgery; ? antibiotics. \\
\hline 2. Airways obstruction - acute or chronic & Physiotherapy; Bronchodilators: Steroids. \\
\hline 3. Chronic Bronchitis & Physiotherapy. \\
\hline $\begin{array}{l}\text { 4. Low Lung Volume - non-obstructive } \\
\text { lung disease, chest wall deformity, } \\
\text { muscle, neuromuscular and neural } \\
\text { diseases affecting respiratory muscle } \\
\text { force }\end{array}$ & Physiotherapy. \\
\hline 5. Smoking & Cessation of smoking. \\
\hline 6. Obesity & Weight reduction. \\
\hline 7. Hypoventilation syndromes & $\begin{array}{l}\text { Physiotherapy; avoid sedative drugs; post- } \\
\text { anaesthetic ventilatory support. }\end{array}$ \\
\hline $\begin{array}{l}\text { 8. Sleep apnoea syndromes - central or } \\
\text { obstructive }\end{array}$ & $\begin{array}{l}\text { Weight loss; surgical treatment of obstruc- } \\
\text { tion; cease alcohol, barbiturates, seda- } \\
\text { tives; ? tracheostomy; physiotherapy. }\end{array}$ \\
\hline 9. Altitude & Consider surgery at sea level. \\
\hline 10. Age & Physiotherapy. \\
\hline \multicolumn{2}{|l|}{ Postoperative only } \\
\hline 11. Abdominal and intrathoracic surgery & $\begin{array}{l}\text { Physiotherapy; consider } \mathrm{O}_{2} \text { therapy; } \\
\text { epidural block. }\end{array}$ \\
\hline 12. Oxygen & $\begin{array}{l}\text { Use controlled } \mathrm{O}_{2} \text { therapy; review } \\
\text { frequently. }\end{array}$ \\
\hline 13. Wound pain & $\begin{array}{l}\text { Consider narcotic infusion; thoracic } \\
\text { epidural. }\end{array}$ \\
\hline 14. Narcotics & $\begin{array}{l}\text { Use narcotic infusion cautiously; relatively } \\
\text { contraindicated in lung disease. }\end{array}$ \\
\hline 15. Other CNS depressant drugs & Avoid if possible. \\
\hline
\end{tabular}

(URTI) characterized by fever, malaise, sore throat, cough and/or sputum, should have elective surgery delayed for at least seven days. Patients recovering from URTI without fever, malaise, or substantial bronchial secretions, should proceed to elective surgery. ${ }^{42}$

The most important and common risk factor is chronic obstructive airways disease (COAD). ${ }^{2,21-23}$ Frequently it co-exists with other important risk factors such as smoking, obesity, hypoventilation, age and abdominal surgery. More recently sleep apnoea syndromes have become recognised as important risk factors. ${ }^{44}$

Many patients without spirometric evidence of COAD will have moderate to severe chronic bronchitis, usually associated with 20 years or more of smoking. Management of COAD patients includes establishing whether a component of reversible obstruction is present by spirometry before and after inhalation of a bronchodilator and by assessing spirometry daily during a weeklong course of intensive physiotherapy.

Cessation of smoking and weight loss are long-term objectives. Little value can be obtained from either one week before the surgery. Nicotine addiction may be a powerful factor mitigating against cessation of smoking and acute nicotine withdrawal symptoms may have their own adverse consequences.

Both COAD patients and chronic bronchitics require intensive chest physiotherapy to reduce airways obstruction and to enhance removal of secretions by coughing and improved mucociliary transport. ${ }^{45}$ Effective physiotherapy requires good personal rapport between patient and physiotherapist. A major component of effective physiotherapy is sustained maximal inspiratory manoeuvres to increase lung volume and to open areas of microatelectasis through the mechanical interdependence of collapsed regions and expanding contiguous functioning alveoli, ${ }^{4}$ and the opening of closed airways in dependent regions.

Postural drainage and chest wall percussion, combined with cough, assist in clearing inspissated secretions from distal airways. ${ }^{2.45}$ Physiotherapy with and without bronchodilator 
therapy has been demonstrated to be effective in reducing the incidence of postoperative atelectasis. ${ }^{22,46-48}$

Preoperative pulmonary assessment and management may be subdivided into three levels of care. Level one care is that provided to all patients who have one or more of the major risk factors enumerated in Table I. Level one care includes physiotherapy, bronchodilator therapy, sputum examination by microscopy and culture of pathogens, baseline chest $x$-ray within the preceding 12 months, spirometry and antibiotics if indicated. The rebreathing $\mathrm{PCO}_{2}$ is a useful additional screening procedure in these patients, particularly if cardiovascular and respiratory disease co-exist. ${ }^{37,49}$

For selected patients with moderate to severe chronic lung disease and cardiovascular disease, scheduled for major abdominal, vascular or thoracic surgery more intensive quantitative assessment available with arterial blood gas analysis may be indicated. ${ }^{49-52}$ Arterial blood gas analysis, together with level one care, constitutes level two care. Level three care includes major lung function tests such as lung volumes, lung mechanics, diffusing capacity, ventilatory response to carbon dioxide and hypoxia, clinical exercise testing, and sleep studies. ${ }^{37,44,53}$ These investigations may be of value in the diagnosis and management of medical problems, but rarely help in the management of surgical interventions. Respiratory outcome following operation is also influenced by a number of non-respiratory factors such as nutritional status. Accordingly, attention to these details is also important in the preoperative preparation of the patient. ${ }^{37}$

The major respiratory goal of intraoperative management of the surgical patient is rapid emergence from anaesthesia, accompanied by a rapid return to adequate normal spontaneous breathing. However, when patients with severe lung disease require major surgery, the decision may be made preoperatively to leave a tracheal tube in situ for 12 to 24 hours after operation to permit maximum efficacy of tracheobronchial toilet and assisted or controlled ventilation, if indicated. The routine use of this approach in large cardiothoracic surgery units is associated with a low incidence of major pulmonary problems in the first 24 hours postoperatively in patients undergoing cardiac surgery.

It is widely believed that local or regional anaesthesia is preferable for interval surgery in the patient with pulmonary disease. This approach is usually appropriate for small peripheral operations, but in many cases is not feasible for major abdominal surgery. There are no good recent clinical or experimental studies to support the use of one or another general anaesthesia technique in these patients. Numerous techniques have been advocated, ranging from 'minimal interference' to 'maximum support. ${ }^{\text {'4-57 }}$ However, it is generally accepted that a judicious combination of relaxants, nitrous oxide and narcotic adjuvants leads to the most rapid emergence from anaesthesia and so permits early cooperation with physiotherapy to establish normal spontaneous ventilation as soon as possible.

Effective physiotherapy must begin as soon as possible after operation. Realistically this means that the anaesthetist and the recovery room nurse encourage deep breathing and coughing as soon as the patient is able to respond. For the patient unable to respond initially due to residual anaesthetic action, nursing in the lateral position is essential to avoid the risk of aspiration.

\section{Oxygen Therapy}

Oxygen therapy is indicated for up to 24 hours after surgery in all patients with lung disease ${ }^{37}$ Patients with specific postoperative complications may require oxygen for more than 24 hours. Although hypoxaemia has been shown to occur in all patients postoperatively, the mechanisms are not entirely clear. ${ }^{58-63}$ These observations have led to the routine use of oxygen after general anaesthesia, but the wisdom of this practice may be questioned for several reasons. First, the recent availability of a robust and reliable oximeter ${ }^{64}$ for clinical use has shown that significant arterial desaturation is uncommon after general anaesthesia, in patients with normal and abnormal lung function. Second, the evidence presented in the first part of this paper indicates the extent to which oxygen enrichment of alveolar gas can accelerate atelectasis. Third, hypoventilation may supervene and lead to respiratory failure if hypoxic drive to breathing is excessively blunted in patients with chronic lung disease. ${ }^{37,65.66}$ Fourth, many investigators illogically recommend oxygen for all patients on the basis of studies that conclude that hypoxia is the major cause of anaesthetic deaths. ${ }^{2,67}$ The illogicality of this recommendation is two-fold. First, it is generally agreed that postoperative hypoxaemia is probably due to a combination of physiological mechanisms such as diffuse microatelectasis, increased mismatching of ventilation and perfu- 
sion in individual alveolo-capillary lung units, and a fall of cardiac output and mixed venous oxygen content. ${ }^{68.69}$ On the other hand, hypoxic anaesthetic deaths are usually catastrophic events related to cardiac arrest and/or unrecognised major airway obstruction. A relationship between relatively minor degrees of postoperative hypoxaemia and major hypoxic catastrophes has not been demonstrated and no good evidence has been adduced to suggest that postanaesthetic oxygen therapy has contributed to a reduction of hypoxia-related deaths after surgery.

These considerations lead to the conclusion that oxygen should only be given to post-surgical patients when indicated specifically. In most cases, oxygen therapy should be controlled - that is, given by masks that use the high air-flow oxygen enrichment venturi principle to provide a constant inspired fractional content of oxygen $\left(\mathrm{FI}_{\mathrm{O}_{2}}\right),{ }^{37,65,66}$ In most patients, 28 per cent oxygen will be adequate and therapy can be discontinued when full recovery of consciousness has occurred. If nitrous oxide has been used during anaesthesia, two to four minutes, only, of 100 per cent oxygen should be given when nitrous oxide is discontinued, to prevent diffusion hypoxia, ${ }^{70-73}$

\section{Analgesia}

The most common method of providing postoperative pain relief is by intermittent intramuscular injection of narcotics. This time-honoured method has little rational basis when drug effect is considered in relation to the pharmacokinetics of the disposition of drugs such as meperidine ${ }^{74}$ and morphine. ${ }^{75}$ These studies showed that a standard intramuscular dose of these agents in surgical patients resulted in a wide spectrum of plasma concentration profiles and clinical effects. The threshold concentration for analgesia has been estimated to be $50 \mathrm{ng} / \mathrm{ml}$ for morphine ${ }^{76}$ and $680 \mathrm{ng} / \mathrm{ml}$ for meperidine, ${ }^{77}$ although in both instances these estimations are crude and open to considerable doubt. Nevertheless, many patients in these studies ${ }^{74-77}$ had plasma concentrations much greater than these thresholds, within 30 minutes of intramuscular injections. In the majority of patients the plasma narcotic concentrations fell rapidly and were less than the analgesia threshold estimates from two to four hours after the injection. Since most postoperative orders stipulate four-hourly injections, intermittent intramuscular injection regimens often provide very high (and occasionally toxic) blood levels in the first hour, and commonly very low levels from 3 to 4 hours, often associated with inadequate relief of pain.

The inadequacy of the four-hourly intramuscular injection regimen was a major motivating factor towards the development of narcotic infusion regimens which Stapleton, et al. (1979) showed to be considerably superior in terms of analgesic efficacy. ${ }^{77}$ However, it is possible that increased analgesic efficacy with these techniques might be associated with increased central respiratory depression and alveolar hypoventilation. ${ }^{78}$ In patients with chronic lung disease and/ or obesity, following abdominal surgery, this represents an increased respiratory hazard which provides a relative contraindication to narcotic infusion, unless it is administered in an intensive care unit environment with regular and effective chest physiotherapy. The relationship of steady state plasma narcotic concentrations to drug effect has not been reported previously. However, recent observations in volunteer subjects indicate an increasing decrement in ventilation and a progressive increase in end-tidal $\mathrm{PCO}_{2}$ and mixed venous $\mathrm{PCO}_{2}$ with increasing steady state meperidine levels up to $1000 \mathrm{ng} / \mathrm{ml} .{ }^{78}$

Narcotic analgesia given by any route in adequate doses can effectively blunt the dull constant pain of a surgical incision. However, it has only a minor effect in reducing the crescendo of pain associated with deep breathing and coughing in the patient who has had abdominal surgery. For this reason, epidural block may be indicated for postoperative pain relief in patients with lung disease who require abdominal surgery and who are elderly, obese and/or potentially uncooperative. ${ }^{37}$

Major improvement in postoperative respiratory care has resulted from increased elective use of postanaesthetic ventilatory support for $\mathbf{1 2}$ to 48 hours postoperatively. ${ }^{55-57,79}$ Nevertheless, ventilatory support and its adjuncts carry a range of associated major potential complications and postanaesthetic ventilation support should not be accepted complacently as a consequence of inadequate preanaesthetic preparation or a faulty anaesthetic technique. ${ }^{37,79}$ The primary goals of perioperative respiratory management - prevention of atelectasis and restoration of adequate spontaneous ventilation - must be constantly kept in mind.

\section{ACKNOWLEDGEMENTS}

Mrs. Marion Wallace and Mrs. K. Peterson 
assisted in the preparation of the manuscript. The Williams \& Wilkins Company, Baltimore, Maryland, gave permission to reproduce Figure 2 from "Respiratory Physiology, The Essentials," by J.B. West.

\section{REFERENCES}

1. James, O.F., Mills, R.M. \& Allen, K.M. Acute respiratory failure in a regional respiratory unit. Anaesth. Intens. Care 5: 372-377 (1977).

2. Pierce, A.K. \& Robertson J. Pulmonary complications of general surgery. Ann. Rev. Med. 28: 211-221 (1977).

3. Fraser, R.G. \& Pare, J.A. Diagnosis of diseases of the chest. W.B. Saunders, Toronto, I: 301-302, (1970).

4. WEST, J.B. Respiratory physiology - the essentials. Williams and Wilkins, Baltimore, Chapter 7 (2nd ed.) (1979).

5. West, J.B. \& Dollery, C.T. Distribution of blood flow and ventilation-perfusion ratio in the lung measured with radioactive $\mathrm{CO}_{2}$. J. Appl. Physiol. 15; 405-410 (1960).

6. Ball, W.C., Stewart, P.B., Newsham, L.G.S. \& Bates, D.V. Regional pulmonary function studied with Xenon. J. Clin. Invest. 41: 519-531 (1962).

7. Kaneko, K, Milic-Emili, J., Dolovich, M.B., Dawson, A. \& Bates, D.V. Regional distribution of ventilation and perfusion as a function of body position. J. Appl. Physiol. 21: 767-777 (1966).

8. Milic-Emill, J., Henderson, J.A.M., Dolovich, M.B., TROP, D. \& KANEKo, K. Regional distribution of inspired gas in the lung. J. Appl. Physiol. 21: $749-759$ (1966).

9. Gale, G.P., Teasdale, S.J., Sanders, D.E., Bradwell, P.J., Russell, A., Solarie, B. \& YORK, J.E. Pulmonary atelectasis and other respiratory complications after cardiopulmonary bypass and investigation of aetiological factors. Can. Anaesth. Soc. 26: 15-21 (1979).

10. WEST, J.B. Respiratory physiology - the essentials. Williams and Wilkins, Baltimore, Chapter 9 (2nd ed.) (1979).

11. FARHI, L. Atmospheric nitrogen and its role in modern medicine. J. Am. Med. Assoc. 188: 984-993 (1964).

12. Husfeld, E. \& Wandall, H.H. Experimental investigations into ventilation of the lung. Acta. Med. Scand. 108: 603-609 (1941).

13. Dale, W.A. \& Rhan, H. Rate of gas absorption during atelectasis. Am. J. Physiol. 170: 606-615 (1952).

14. Comroe, J.H. JNR. \& Dripps, R.D. Physiological basis for oxygen therapy. Charles $C$. Thomas, Springfield, Illinois (1960).

15. RahN, H. \& FarhI, L.E. Gaseous environment and atelectasis. Fed. Proc. 22: 1035-1041 (1963).

16. Ernsting, J. Some effects of oxygen breathing in man. Proc. Roy. Soc. Med. 53: 96-98 (1960).

17. Langdon, D.E. \& Reynolds, G.E. Post flight respiratory symptoms associated with $100 \%$ oxygen and $\mathrm{G}$ forces. Aerospace Med. 32: 713-718 (1961).

18. Bendixen, H.H., Hedley-White, J., Chir, B.
\& LAVER, M.B. Impaired oxygenation in surgical patients during general anaesthesia with controlled ventilation: a concept of atelectasis. N. Engl. J. Med. 269: 911-996 (1963).

19. Robertson, W.G. \& Farhi, L.E. Effect of ambient pressure on rate of collapse of rat lung. Physiologist 4: 95 (1961).

20. Mead, J. \& Collier, C. Relation of volume history of lungs to respiratory mechanics in anaesthetized dogs. J. Appl. Physiol. 14: 669-678(1959).

21. Meneely, G.R. \& Ferguson, J.L. Pulmonary evaluation and risk in patient preparation for anesthesia and surgery. J. Am. Med. Assoc. 175: 1074-1080 (1961).

22. Stein, M., Koota, G.M., Simon, M. \& Frank, H.A. Pulmonary evaluation of surgical patients. J. Am. Med. Assoc. 181: 765-770 (1962).

23. Lattimer, R.G., Dickman, M., Day, W.G., GunN, M.L. \& SchmidT, C.D. Ventilatory patterns and pulmonary complications after upper abdominal surgery determined by preoperative and postoperative computerized spirometry and blood gas analysis. Am. J. Surg. 122: 622-63 (1971).

24. Anscombe, D.R. \& Buxron, R. ST. J. Effect of abdominal operations on total lung capacity and its subdivisions. Br. Med. J. 2: 85-86 (1958).

25. LEWIS, F.J. \& WELCH, J.A. Respiratory mechanics in postoperative patients. Surg. Gynecol. Obstet. 120: 305-314 (1965).

26. Pierce, J.A. \& Garofolo, M.L. Preoperative medication and its effect on blood gases. J. Am. Med. Assoc. 194: 99-102 (1965).

27. Egbert, L.D. \& Bendixen, H.H. Effect of morphine on breathing pattern, a possible factor in atelectasis. J. Am. Med. Assoc. 188: 485-487 (1964).

28. Bendixen, H.H., Smith, G.M. \& Mead, J. Pattern of ventilation in young adults. J. Appl. Physiol. 19: 195-198 (1964).

29. RIGG, J.R.A. Ventilatory effects and plasma concentration of morphine in man. $\mathrm{Br}$. J. Anaesth 50 : 759-765 (1978).

30. RIGG, J.R.A. Low ventilatory response to carbon dioxide is not associated with increased ventilatory depression by morphine. $\mathrm{Br}$. J. Anaesth. 50: 767-771 (1978).

31. RigG, J.R.A. \& Goldsmith, C.H. Recovery of ventilatory responses to $\mathrm{CO}_{2}$ after thiopentone, morphine and fentanyl in man. Canad. Anaesth. Soc. J. 23: 370-382 (1976).

32. Bunker, J.P., Bendixen, H.H., Sykes, M.K., TODD, D.P. \& SURTESSES, A.D. A comparison of ether anaesthesia with thiopental-nitrous oxidesuccinylcholine for upper abdominal surgery. Anesthesiology 20:745-752 (1959).

33. Eldridge, F.L. \& Davis J.M. Effect of Mechanical factors on respiratory work and ventilatory responses to $\mathrm{CO}_{2}$. J. Appl. Physiol. 14: 721-726 (1959).

34. Lourenco, R.V., Cherniack N.S., Malm J.R. \& FISHMAN A.P. Nervous output from the respiratory centre during obstructed breathing. J. Appl. Physiol 21: 527-533 (1966).

35. Stanley, N.N., Cunningham E.L., Altose M.D., KelSen S.G., Levinson R.S. \& ChERNIACK N.S. Evaluation of breath holding in hyper- 
capnia as a simple clinical test of respiratory chemosensitivity. Thorax 30: 337-343 (1975).

36. Cherniack R.M. \& SNIDAL D.P. The effect of obstruction to breathing on the ventilatory reponse to $\mathrm{CO}_{2}$. J. Clin. Invest. 35: 1286-1290 (1956).

37. RIGG, J.R.A.\& JONES, N.L. Clinical assessment of respiratory function. $\mathrm{Br}$. J. Anaesth. 50: 3-13 (1978).

38. Pooler, H.E. Relief of postoperative pain and its influence on vital capacity. Br. Med. J. 2: $1200-1203$ ( 1949).

39. Wightman, J.A.K. A prospective survey of the incidence of postoperative pulmonary complications. Br. J. Surg. 55: 85-91 (1968).

40. Marshall, B.E. \& Miller, R.A. Some factors influencing postoperative hypoxaemia. Anaesthesia. 20: 408-428 (1965).

41. CAHILL, J.M. Respiratory problems in surgical patients. Am. J. Surg. 116: 362-368 (1968).

42. Steward, D.J. \& Sloan, I.A.J. Recent upper respiratory infection and pulmonary artery clamping in the aetiology of postoperative respiratory complications. Canad. Anaesth. Soc. J. 16: 57-60 (1969).

43. Chalon, J., Tayyab, M.A. \& Ramanathan, S. Cytology of respiratory epithelium as a predictor of respiratory complications after operation. Chest 67: 32-35 (1975).

44. Sullivan, C.E. Disorders of breathing in sleep. Mod. Med. Aust., March 1980: 7-17.

45. Oldenburg, F.A. Jnr., Dolovich, M.B., MontGOMERY, J.H. \& Newhouse, M.T. Effects of postural drainage, exercise and cough on mucus clearance in chronic bronchitis. Am. Rev. Resp. Dis. 120: 739-745 (1979).

46. THOREN, L. Postoperative pulmonary complications. Observations on their prevention by means of physiotherapy. Acta. Chir. Scand. 107: 193-205 (1954).

47. PALMER, K.N.V.\& Sellick, B.A. The prevention of postoperative pulmonary atelectasis. Lancet 1 : $164-168(1953)$.

48. Stein, M. \& Cassara, E.L. Preoperative pulmonary evaluation and therapy for surgery patients. J. Am. Med. Assoc. 211: 787-790 (1970).

49. Powles, A.C.P. \& Campbell, E.J.M. An improved rebreathing method for measuring mixed carbon dioxide tension and its clinical application. Can. Med. Assoc. J. 1/8: 501-504 (1978).

50. Davis, C.C., Jones, N.L. \& SEaley, B.S. Measurements of cardiac output in seriously ill patients using a $\mathrm{CO}_{2}$ rebreathing method. Chest 73 : 167-172 (1978).

51. Franciosa, J.A. Evaluation of the $\mathrm{CO}_{2}$ rebreathing cardiac output method in seriously ill patients. Circulation 55: 449-455 (1977).

52. Powles, A.C.P., Hershler, R. \& Rigg, J.R.A. A pocket calulator programme for bedside estimation of cardiopulmonary functions. Comp. Biol. Med. 10: 143-151 (1980).

53. Jones, N.L., Campbell, E.J.M., Edwards, R.H.T. \& RoberTson D.G. Clinical exercise testing. W.B. Saunders, Philadelphia (1975).

54. NunN, J.F. Anaesthesia for Patients with Respiratory Disease. In: General Anaesthesia, 3rd Ed. T.C. Gray \& J.F. Nunn. Butterworths, London (1971).

55. Holaday, D.A. \& RatTenboRG, C.C. Selection of a method of anaesthesia for patients with pulmonary dysfunction. In: Lung Disease, Clinical Anaesthesia series, Vol. I. ed. by D.A. Holaday, Oxford: Blackwell (1967).

56. Utting, J.E., Gray, T.C. \& Rees, G.J. Anaesthesia for the respiratory cripple. Acta. Anaesth. Scand. 9: 29-38 (1965).

57. Thornton, J.A. The problem of general anaesthesia in patients with chronic respiratory disease. Thorax. 24: 380 (1969).

58. NunN, J.F. \& PAYNe, J.P. Hypoxaemia after general anaesthesia. Lancet 2: 631-632 (1962).

59. NuNN, J.F. Factors influencing the arterial oxygen tension during halothane anaesthesia with spontaneous respiration. $\mathrm{Br}$. J. Anaesth. 36: 327-41 (1964).

60. NuNN, J.F. Influence of age and other factors on hypoxia in the postoperative period. Lancet 2 : 466-468 (1965).

61. Nunn, J.F., Bergman, N.A. \& Coleman, A.J. Factors influencing the arterial oxygen tension during anaesthesia with artificial ventilation. $\mathrm{Br}$. J. Anaesth. 37: 898-914 (1965).

62. Diament, M.L. \& Palmer, K.N.V. Venous/arterial pulmonary shunting as the principal cause of postoperative hypoxaemia. Lancet I: 15-17 (1967).

63. Thompson, D.S. \& EAson, C.N. Hypoxaemia immediately after operation. Am. J. Surg. 120: 649-651 (1970)

64. Saunders, N.A., Powles, A.C.P. \& Rebuck, A.S. Ear oximetry: accuracy and practicability in the assessment of arterial oxygenation. Am. Rev. Resp. Dis. 113: 745-749 (1976).

65. Campbell, E.J.M. The management of acute respiratory failure in chronic bronchitis and emphysema. Am. Rev. Resp. Dis. 96: 626-639 (1967).

66. LElGH, J. Oxyten therapy at ambient pressure. In: Scientific Foundations of Anaesthesia, Heinemann, London, pp. 200-205 (1975).

67. Bendixen, H.H. \& LAver, M.B. Hypoxia in anaesthesia. Clin. Pharmacol. Ther. 6: 510-539 (1965).

68. Kleman, G.R., NunN, J.F., Prys-Roberts, C. \& GREENBAUM, R. The influence of cardiac output on arterial oxygenation. Br. J. Anaesth. 39: 450-458 (1967).

69. Philbin, D.M., Sullivan, S.F., Bowman, F.O. Malm, J.R. \& Papper, E.M. Postoperative hypoxaemia; contribution of the cardiac output. Anesthesiology, 32: 136-142 (1970).

70. Rackow, H., Salanitre, E. \& Frumin, M.J Dilution of alveolar gases during nitrous oxide excretion in man. J. Appl. Physiol. 16: 723-728 (1961).

71. FINK, B.R. Diffusion anoxia. Anesthesiology 16: 511-519 (1955).

72. Sheffer, J., Steffenson, J.L. \& BırCh, A.A. Nitrous oxide induced diffusion hypoxia in patients breathing spontaneously. Anesthesiology 37: 436-439 (1972).

73. Frumin, M.J. \& Edelist, G. Diffusion anoxia: a critical appraisal. Anesthesiology 31: 243-249 (1969).

74. Mather, L.E., Lindop, M.J., Tucker, G.T. \& Pflug, A.E. Pethidine revisited: plasma concentration and effects after IM injections. $\mathrm{Br}$. J. Anaesth. 47: 1269-1275 (1975).

75. Rigg, J.R.A., Browne, R.A., Davis, C., Khan- 
DELWAL, J.K. \& GOLDSMiTH, C.H. Variation in the disposition of morphine fter IM administration in surgical patients. Br. J. $/$ naesth. $50: 1125-1130$ (1978).

76. Berkowitz, B.A., NGai, S.H., YANG, J.C., Hampstead, J. \& Spector, S. The disposition of morphine in surgical patients. Clin. Pharmacol. Ther. 17:629-635 (1975).

77. Stapleton, J.V., Austin, K.L., Mather, L.E. A pharmacokinetic approach to postoperative pain: continuous infusion of pethidine. Anaesth: Intens. Care 7: 25-32 (1979).

78. RigG, J.R.A., Vedig, A.E. \& ILSLEY, A.H. Relationship of steady state plasma pethidine concentrations to ventilatory effects of pethidine. Brit. J. Anaesth, accepted for publication, 1981.

79. Pontoppidan, H., Geffin, B. \& Lowenstein, E. Acute respiratory failure in the adult. Little Brown, Boston (1973).

\section{RÉSUMÉ}

Ce travail présente une discussion des mécanismes physiopathologiques de l'atélectasie pulmonaire ainsi que des facteurs de risque prédisposant au collapsus pulmonaire. Les différentes approaches en vue d'éliminer ou d'atténuer les effets des facteurs de risque et de prévenir le collapsus pulmonaire sont également discutées dans l'optique de leur mécanisme d'action.

L'instabilité de l'alvéole pulmonaire est la conséquence naturelle des phénomènes de tension de surface associés aux différences régionales de diamètre alvéolaire. Cette tendance naturelle au collapsus alvéolaire est amplifiée en présence des facteurs de risque suivants: bas volumes pulmonaires, hauts volumes de fermeture, oxygénothérapie, ventilation rapide et superficielle, pathologies pulmonaires chroniques, tabac, obésité, douleurs post-opératoires en chirurgie abdominale ou thoracique, atteintes neurologiques, neuro-musculaires ou musculo-squelettiques avec répercussions sur la ventilation.

Les soins respiratoires péri-opératoires sont axés sur la prévention de l'atélectasie pulmonaire. A cet effet on recommande la physiothérapie et la remise à plus tard des cas de chirurgie élective lorsqu'une amélioration significative de la fonction respiratoire est possible avec une thérapie spécifique (antibiotiques, broncho-dilatateurs, stéroïdes, diminution du tabac et de l'apport calorique). Dans certains cas particuliers un support ventilatoire post-opératoire avec respiration contrôlée peut être indiqué. 